\title{
EVALUATION OF PATIENTS UNDERGOING FIXATION OF DIAPHYSEAL HUMERAL FRACTURES USING THE MINIMALLY INVASIVE BRIDGE-PLATE TECHNIQUE
}

Mauro José Superti ${ }^{1}$, Fábio Martynetz², Ricardo Sprenger Falavinha ${ }^{3}$, Rodrigo Caldonazzo Fávaro ${ }^{4}$, Luis Felipe Villas Boas ${ }^{4}$, Salim Mussi Filho ${ }^{3}$, Juliano Martynetz ${ }^{5}$ Bruno Ribas $^{6}$

\section{ABSTRACT}

Objective: The aim was to describe the experience of our group in treating humeral shaft fractures using the bridge-plate technique via an anterior approach. Methods: Seventeen patients with acute diaphyseal humeral fractures with an indication for surgical treatment who were operated in 2006-2010 were evaluated. The AO and Gustilo \& Anderson classifications were used. All the patients were operated using the anterior bridge-plate technique and completed a follow-up period of at least twelve months. Results: Sixteen men and one woman were treated. Their mean age was 31.8 years (18-52). Among the injury mechanisms found were: five motorcycle accidents, four car accidents, three fractures due to firearm projectiles, two falls to the ground and finally, with one case each, assault, crushing and being run over. Eight pa- tients had open fractures: two grade I, one grade II, four grade IIIa and one grade IIIb, according to the Gustilo-Anderson classification. In relation to the AO classification, we found: one $12 \mathrm{~A} 1$, three $12 \mathrm{~A} 2$, four $12 \mathrm{~A} 3$, one $12 \mathrm{~B} 1$, four $12 \mathrm{~B} 2$, three $12 \mathrm{~B} 3$ and one $12 \mathrm{C} 2$. The mean postoperative follow-up was 25 months (12-48). As complications, two patients had pain in the elbow and a ROM deficit and one had deep infection. The mean time taken to achieve consolidation was 17.5 weeks. There was no loss of reduction, pseudarthrosis or malunion in this series of patients. Conclusion: The authors believe that the technique described has low rates of complications and morbidity, with good initial results, although the series is limited by the small sample.

Keywords - Humeral Fractures; Fracture Fixation, Internal; Surgical Procedures, Minimally Invasive

\section{INTRODUCTION}

Diaphyseal fractures of the humerus occur frequently and represent three to five percent of the fractures of the human body. They present a bimodal peak, i.e. one time of highest incidence between the second and third decades of life and another between the sixth and eighth decades ${ }^{(1)}$.

The humerus is a well vascularized bone that is surrounded by several muscles, which facilitates the consolidation process. The great majority of diaphyseal fractures of the humerus present good results with conservative treatment ${ }^{(2-5)}$. The main methods of nonsurgi- cal treatment are immobilization using a Velpeau sling, U-shaped plaster cast splint, thoracobrachial plaster cast, hanging plaster cast and brachial orthoses ${ }^{(2)}$.

The surgical approach is reserved for specific cases: exposed fractures ${ }^{(1,6)}$, segmental fractures, pathological fractures, fractures associated with vascular lesions, bilaterality ${ }^{(1,2)}$, impossibility of correcting an angular displacement greater than $15^{\circ}$ with a functional orthosis, presence of rotational displacement, multiple trauma, bone failure or diastasis at the focus, obesity, floating elbow, nerve injuries and failure of conservative treatment ${ }^{(1,2,6,7)}$.

1 - Head of the Shoulder and Elbow Group, Orthopedics and Traumatology Service, Cajuru University Hospital, Curitiba, PR, Brazil.

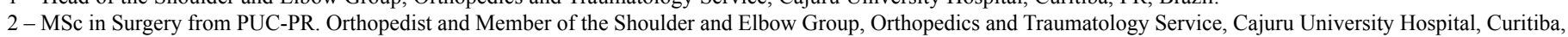
PR, Brazil.

3 - Orthopedist and Member of the Shoulder and Elbow Group, Orthopedics and Traumatology Service, Cajuru University Hospital, Curitiba, PR, Brazil.

4 - Third-year Resident in the Orthopedics and Traumatology Service, Cajuru University Hospital, Curitiba, PR, Brazil.

5 - Fourth-year Resident in the Orthopedics and Traumatology Service, Cajuru University Hospital, Curitiba, PR, Brazil.

6 - Undergraduate Student in the Medical Course, PUC-PR, Curitiba, PR, Brazil.

Work performed at Cajuru University Hospital, Curitiba, PR

Correspondence: Rua Candido Xavier 192, Batel 1240, Ap. 34, 80240-280 Curitiba, PR, Brazil. E-mail: membrosuperior@vegaturbo.com.br

Work received for publication: December 15, 2011; accepted for publication: April 19, 2012.

The authors declare that there was no conflict of interest in conducting this work 
Surgical treatment involves different concepts and techniques. The implants used may provide relative or absolute stability to the fracture line. Many studies have compared the results between compression plates (a method providing absolute stability that is well established in the literature) and intramedullary nails ${ }^{(1,2,6,8-11)}$. The latter emerged as a therapeutic option in the 1980s, making use of the principle of relative stability.

To achieve absolute stability with compression between fragments using compression plates, anatomical reduction is necessary. This procedure presents certain disadvantages: it requires direct exposure of the fracture focus, together with greater manipulation and injury to soft tissues; it presents greater risk of injury to the radial nerve; it presents poor fixation in osteoporotic bone; and it requires an operation of longer duration ${ }^{(3,6,11,12)}$.

Intramedullary nails use the principle of relative stability and are minimally invasive ${ }^{(2,12)}$. They do not expose the hematoma of the fracture ${ }^{(3,4,10)}$ and there is less risk of nerve injury ${ }^{(3)}$. However, this procedure has the disadvantages of requiring the use of an image intensifier and specific positioning for the patient ${ }^{(13)}$, and presents the risk of new fracturing at the time of inserting the retrograde nail ${ }^{(6,11)}$.

With the nail insertion technique, the adjacent joint is invaded, which may lead to pain and stiffness. Nails that are inserted in an anterograde manner present the risk of injuring the rotator cuff, while retrograde nails present the risk of elbow stiffness and a greater rate of fracture non-consolidation ${ }^{(3,6,7,11,13)}$.

Recently, in seeking minimally invasive techniques, a new therapeutic option has arisen for treating these fractures: bridge plates ${ }^{(14,15)}$. This technique brings together the ease of handling of plates and the relative stability principle of nails. Although there are still only a few studies on this, the initial results have been very satisfactory.

The aim of the present study was to report the experience of our shoulder and elbow surgery group relating to treatment of diaphyseal fractures of the humerus, by means of the bridge plate technique, using an anterior route.

\section{MATERIALS AND METHODS}

Between July 2006 and September 2010, the Shoulder and Elbow Surgery Group of the Department of Orthopedics and Traumatology of Cajuru University Hospital conducted a longitudinal retrospective epidemiological study through reviewing the medical files.

This study was approved by the Ethics Committee of the Pontificate Catholic University of Paraná.

\section{The inclusion criteria were that the cases should involve:}

1) diaphyseal fractures of the humerus with a surgical indication that were attended at our service and were treated using the bridge plate method, using an anterior route; 2) length of evolution of less than 15 days until surgery; 3) skeletally mature patients; and 4) fractures with a safety margin of $4.5 \mathrm{~cm}$ to the lesser tuberosity in the proximal fragment, and the same amount to the olecranon fossa in the distal fragment.

\section{The exclusion criteria were the following:}

1) postoperative follow-up of less than 12 months; 2) fractures with more than 15 days of evolution; 3 ) skeletally immature patients; 4) poor bone quality; 5) pseudarthrosis or delayed consolidation; 6) pathological fractures; and 7) fractures in which the line compromised the safety margin.

Using these criteria, 17 patients (16 men and one woman) were included in our sample.

The patients were attended in the emergency service in accordance with the Advanced Trauma Life Support (ATLS) protocol. In cases of exposed fractures, intravenous antibiotics were firstly administered in the multiple trauma room, using a therapeutic regimen in accordance with the protocol of the service. The patients were then taken to the surgical center for lavage and debridement of the wound.

Indication of an external fixator at the time when the patient was admitted was reserved for cases in which there was extensive injury to soft tissues and when the patient presented multiple trauma, thus necessitating damage control. Patients presenting favorable soft-tissue conditions were treated surgically on admission. The other patients were immobilized provisionally, and were treated surgically within a maximum of 15 days.

\section{Statistical methodology}

The nonparametric Mann-Whitney test was used for the statistical analysis.

\section{Operative technique}

The patient was positioned in dorsal decubitus and plexus anesthesia was administered. Antibiotic prophylaxis consisting of $1 \mathrm{~g}$ of intravenous cefazolin was administered after the anesthetic procedure.

The surgical technique that we used was similar to the technique described by Livani and Belangero ${ }^{(13)}$.

Firstly, a proximal access was constructed (Figure 1), of around $5 \mathrm{~cm}$ between the lateral border of the biceps brachialis muscle and the tendon of the deltoid muscle. 
After making the skin incision, the biceps and the cephalic vein were pushed away medially and the deltoid, laterally. In this manner, humeral diaphysis became exposed.

A distal access (Figure 1) was constructed just after this, also of around $5 \mathrm{~cm}$, on the lateral face of the tendon of the biceps brachialis. After making the skin incision, the biceps brachialis muscle was pushed away medially to expose the brachial muscle. The lateral cutaneous nerve of the forearm was pushed away medially and the brachial muscle was divided in the middle, thus exposing the humeral diaphysis.

After constructing an extraperiosteal tunnel between the two incisions using a dilatation instrument, the plate was slid in percutaneously, from distal to proximal. The fractures were reduced with the aid of radioscopy. Livani and Belangero ${ }^{(13)}$ used a different technique, in which they introduced the plate according to the fracture line. In low fractures, the plate was slid in from distal to proximal.

DCP plates were used, of length $4.5 \mathrm{~mm}$ (12 or 14 holes). The plate was positioned over the anterior surface of the humerus.

The number of screws used for fixation varied according to the safety margin. This was established as $4.5 \mathrm{~cm}$ between the end of the fracture line and the lesser tuberosity, in the proximal fragment, or the olecranon fossa in the distal fragment. We took this measure because this was the minimum bone length for using three screws in the DCP plate of length $4.5 \mathrm{~mm}$.

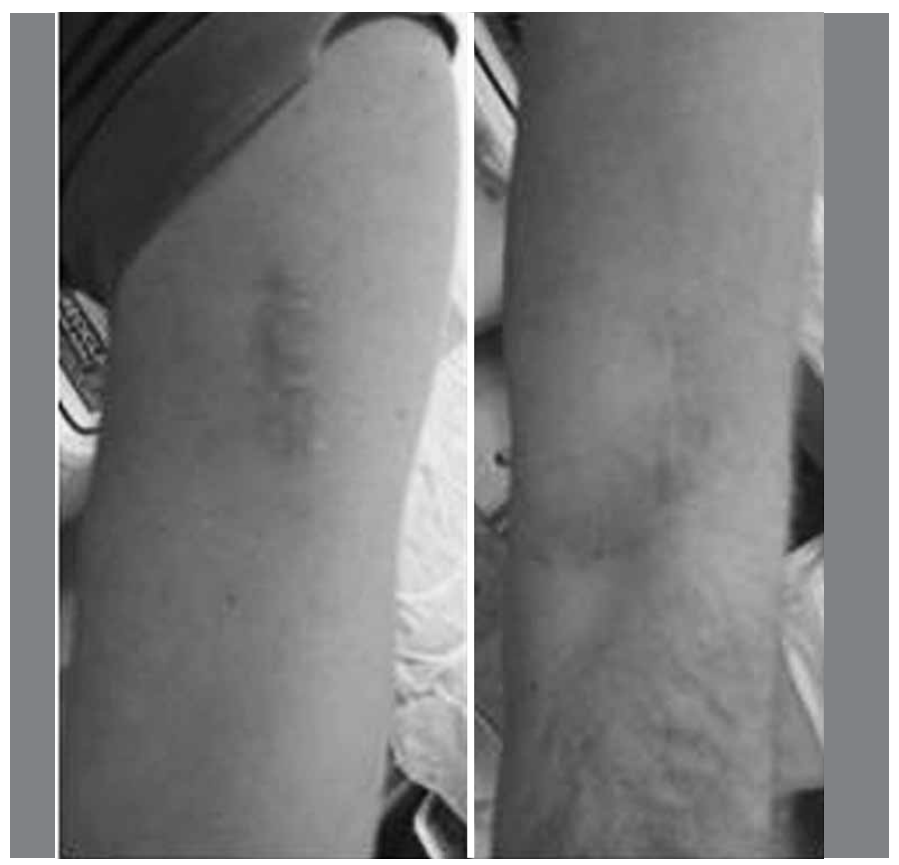

Figure 1 - Proximal and distal accesses. Source: Present author.
In cases of fractures with lines that were more peripheral, presenting limited space for a safety margin, three screws were used and all the orifices of the segment proximal to the joint were filled. In situations with a larger segment, two or three screws were used, intercalated with the greatest possible number of empty orifices.

Medial-diaphyseal fractures were fixed using four screws (two proximally and two distally), leaving the greater possible number of empty orifices intercalating the screws.

After the reduction had been verified using radioscopy, the stability of the synthesis was tested by means of combined elbow and shoulder movements. Finally, the subcutaneous cellular tissue and the skin were sutured using Vicryl ${ }^{\circledR} 2.0$ and Nylon ${ }^{\circledR} 3.0$, respectively.

The patients were kept in hospital for 24 to 48 hours, receiving analgesia and the antibiotic regimen. No type of postoperative immobilization was used, and the patients were encouraged to make simple active movements of the elbow and shoulder, while avoiding loading them. The patients were followed up by the physiotherapeutic professional from the immediate postoperative period onwards.

Reassessments were made two and six weeks after the operation, and then every six weeks until fracture consolidation had been achieved. After consolidation had been demonstrated, the patient was released to make movements with full load-bearing, and return visits were made every three months.

The patients were assessed in relation to their elbow and shoulder ranges of motion, occurrences of complications, fracture consolidation, satisfaction with the treatment and return to work activities (Figure 2).

\section{RESULTS}

Among the 17 patients evaluated, 16 were male and one was female. The patients' mean age was 31.8 years, ranging from 18 to 52 years. The length of follow-up ranged from 12 to 48 months, with a mean of 25 months.

The lesion mechanisms found most often were motorcycle and car accidents, accounting for five (29.4\%) and four $(23.5 \%)$ patients, respectively, followed by firearm projectiles in three cases $(17.6 \%)$ and falls to the ground in two cases $(11.8 \%)$. The least frequent injuries were due to aggression, crushing and being run over, with one patient each (5.9\%) (Figure 3).

\section{Associated lesions}

Among the 17 patients, nine (52.9\%) presented preoperative associated injuries. Injury to the radial nerve 


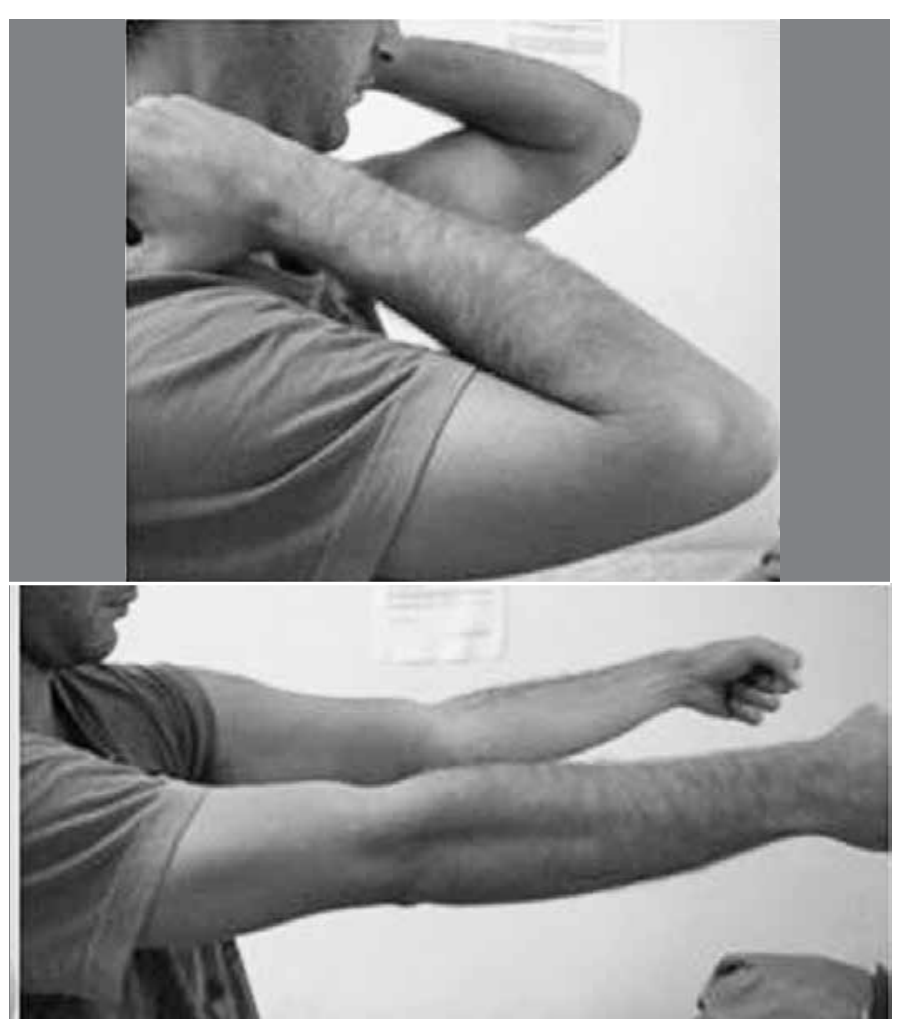

Figure 2 - Patient three months after the operation, showing range of motion of $140^{\circ}$ for elbow flexion.

Source: Present author.
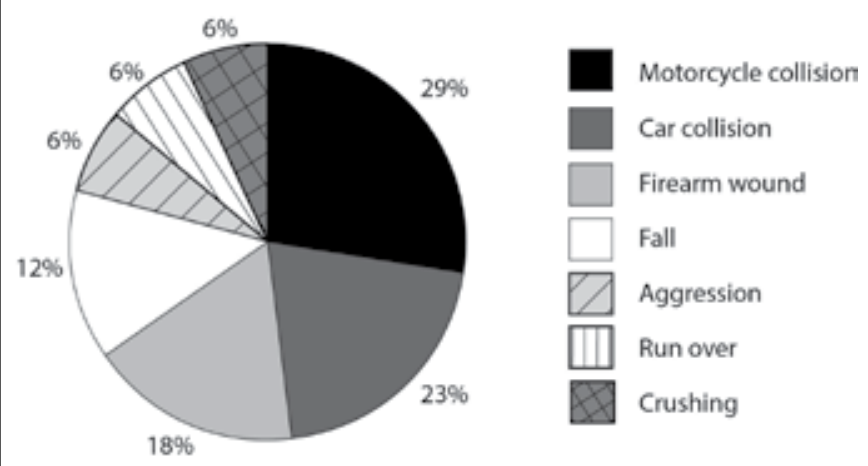

Figure 3 - Injury mechanisms.

Legenda: $F A F=$ Ferimento por arma de fogo.

Source: Present author.

was the commonest of these. This was present in three patients, thus representing $33.3 \%$ of all the associated injuries. Two of these patients were victims of firearm wounds and presented neuropraxia that spontaneously resolved over a two-month period. One patient had suffered a fall to the ground and presented a complex deficit of strength and sensitivity in the radial myotomes and dermatomes. During the operation on this patient, the nerve was seen to have thinned, with hematoma, and was trapped at the focus of the fracture. This patient did not recover radial function and underwent tendon transposition five months after the operation.

In comparing the nerve lesions (Table 1) with the fracture line as classified by the AO Group, the following was observed: three patients presented type A3 fractures, and one of these $(33.3 \%)$ presented neuropraxia of the radial nerve; among four patients with type A3 fractures, one $(25 \%)$ presented a permanent injury to the radial nerve; and one patient $(33.3 \%)$, out of a total of three who suffered type B3 fractures, presented neuropraxia of the radial nerve.

One patient who suffered a car accident presented injuries to the spleen and liver and a series of lesions on his back. One patient who was a victim of being run over, suffered an exposed fracture of the humerus and forearm (floating elbow). Both were classified as Gustilo and Anderson grade IIIB.

Cranioencephalic trauma, an exposed fracture of the thumb, an injury to an extensor tendon and contralateral acromioclavicular dislocation conclude the list of associated injuries, with one patient each.

Table 1 - Relationship between preoperative nerve injuries and the type of fracture, according to the AO Group classification.

\begin{tabular}{c|c|c|c|c|c|c|c}
\hline & A1 & A2 & A3 & B1 & B2 & B3 & C2 \\
\hline $\mathbf{F x}$ & 1 & 3 & 4 & 1 & 4 & 3 & 1 \\
\hline $\mathbf{N}^{(1)}$ & - & $1^{(2)}$ & 1 & - & - & $1^{(2)}$ & - \\
\hline$\%$ & - & 33.3 & 25.0 & - & - & 33.3 & - \\
\hline
\end{tabular}

Legend: $\mathrm{Fx}=$ Number of fractures; $\mathrm{N}=$ Number of cases of neuropraxia; \% = Percentage of neuropraxia; (1) All the injuries were to the radial nerve; (2) Neuropraxia. Source: Present author.

\section{Classification}

Closed fractures were slightly in the majority in this study (52.9\%). Exposed fractures, as classified by Gustilo and Anderson, were presented by $47.1 \%$ of the patients. Two patients (11.8\%) presented grade I (GI) exposure. A single patient (5.9\%) presented grade II (GII). Five patients presented grade III (GIII), and four of them were classified as GIIIA and GIIIB (Figure 4).

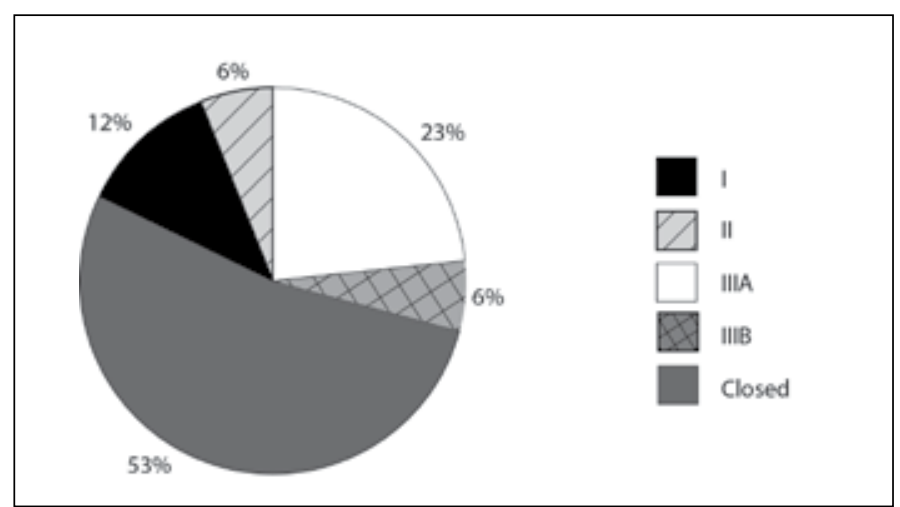

Figure 4 - Percentages of fractures according to Gustilo and Anderson classification. Source: Present author. 
According to the AO Group classification, eight patients $(47 \%)$ presented a type A fracture line (four A3, three A2 and one A1). Another eight patients (47\%) were type B (four B2, three B3 and one B1). Only one patient presented fracture type $\mathrm{C} 2$ (Figure 5).

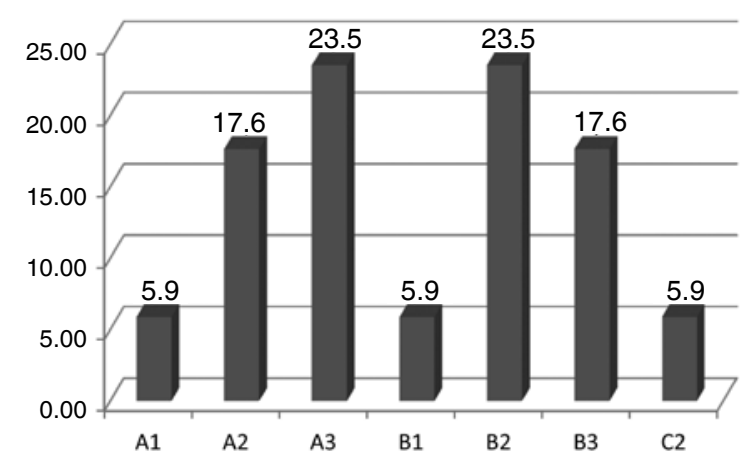

Figure 5 - Percentages of fractures according to the AO System classification.

Source: Present author.

\section{Time taken to reach consolidation}

The mean time taken for consolidation to be achieved was 17.5 weeks, with a range from seven to 32 weeks (Figure 6). In relation to the AO Group classification, the single fracture of type A1 consolidated in 12 weeks. The fractures of type A2 presented a mean time to consolidate of 13 weeks (range: 7-20). The A3 fractures had a mean of 18.5 weeks (range: 13-21).

The single patient with fracture type B1 achieved consolidation in 32 weeks. This was a patient with an exposed fracture of type GIIIB who evolved with infection. Among the four patients with fractures of type B2, the mean time taken for consolidation to be achieved was 16.2 weeks (range: 12-25). The fractures of type B3 consolidated over a mean time of 18.6 weeks (16-24). The single fracture of type $\mathrm{C} 2$ consolidated in 20 weeks.

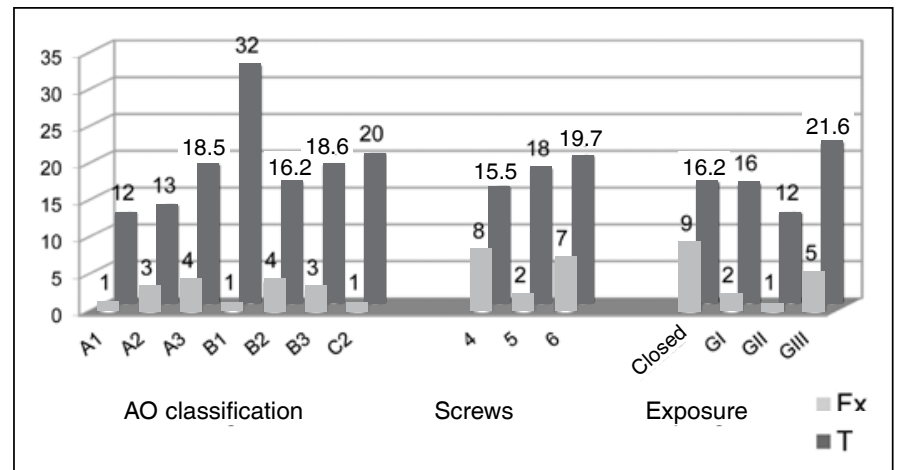

Figure 6 - Time taken for consolidation to be achieved in relation to the AO classification, the number of screws and the Gustilo and Anderson classification.

Legend: $\mathrm{Fx}=$ number of fractures; $\mathrm{T}=$ time taken for consolidation to be achieved (mean in weeks).

Source: Present author.
In relation to fracture exposure, the closed fractures consolidated over a mean time of 16.2 weeks (range: 7-25). Among the exposed fractures, the GI fractures consolidated over a mean of 16 weeks (range: 12-20). The single GII fracture consolidated in 12 weeks. The GIII fractures consolidated over a mean time of 21.6 weeks (range: 16-32). If only the GIIIA fractures were taken into consideration, the mean dropped to 19 weeks (range: 16-24). This was because the single GIIIB fracture evolved with infection, and the synthesis had to be exchanged for external fixation. This fracture consolidated in 32 weeks. There was no statistically significant difference in the time take for consolidation to be achieved in relation to the degree of exposure of the fractures $(p=0.606)$.

Patients with associated injuries presented longer times to reach consolidation than did patients who only had a humeral fracture (Table 2). For the patients who presented associated injuries, the mean time taken was 19.2 weeks (range: 12-32). On the other hand, for the patients with a single fracture, the mean time taken was 15.6 weeks (range: 7-20). Considering only the patients whose associated lesion was neuropraxia, the mean time taken to achieve consolidation was 18.6 weeks (range: 16-20). There was no statistically significant difference in the time taken until consolidation, in relation to the presence of associated injuries $(p=0.370)$.

Table 2 - Associated injuries vs. consolidation.

\begin{tabular}{c|c|c|c|c}
\hline & N & T & Var & p \\
\cline { 1 - 3 } Without injuries & 8 & 15.6 & $7-20$ & \\
\cline { 1 - 3 } With injuries & 9 & 19.2 & $12-32$ & \multirow{2}{*}{0.35} \\
\cline { 1 - 3 } With neuropraxia & 3 & 18.6 & $16-20$ & \\
\hline
\end{tabular}

Legend: $\mathrm{N}=$ number of patients; $\mathrm{T}$ = Time taken for consolidation to be achieved (mean in weeks); Var $=$ variation; $p=p$ value.

Source: Present author.

With regard to the number of screws used, seven patients' fractures were fixed with four screws (Figure 7) and the mean time taken for consolidation to be achieved in these cases was 15.5 weeks (range: 7-25). For the two cases of fractures fixed with five screws, the mean was 18 weeks (range: 16-20). Among the eight patients fixed with six patients, the mean was 19.7 weeks (range: 12-32).

\section{Complications}

Three patients $(17.6 \%)$ presented postoperative complications. In relation to the degree of exposure, one case of a closed fracture and one case each of 


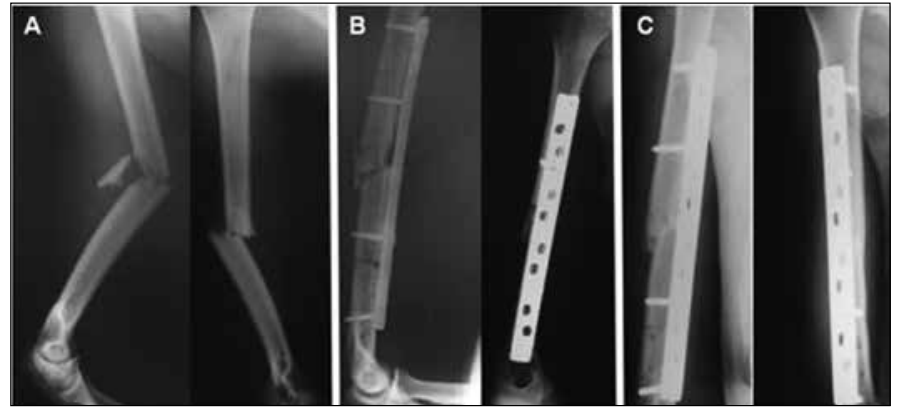

Figure 7 - Radiographs on 39-year-old male patient who was a victim of a motorcycle accident.

Legend: $\mathrm{A}=$ initial radiographs showing a fracture classified as $\mathrm{AO} 12 \mathrm{~B} 2 ; \mathrm{B}=$ fracture immediately after the operation, treated using a long plate with two proximal screws and two distal screws; $\mathrm{C}=12$ months after the operation, the fracture presented radiographic signs of consolidation.

Source: Present author.

grades I and IIIB fractures presented complications (Table 3). In relation to the AO classification, the single patient with a B1 fracture presented a complication. One $(25 \%)$ of the four patients classified as B2 and the single patient classified as $\mathrm{C} 2$ had a complication.

In terms of the number of screws used to fix the fracture, one patient (12.5\%) fixed with four screws presented pain and diminished ROM. Two patients $(28.6 \%)$ fixed with six screws had complications. One of them had pain and diminished ROM, such that it became necessary to remove the synthesis material. After the procedure, this patient evolved with neuropraxia of the radial nerve. The other patient presented infection.

Table 3 - Number of complications in relation to the degree of exposure of the fracture.

\begin{tabular}{c|c|c}
\hline Exposure & $\mathbf{N}$ & $\%$ \\
\hline I & $1^{(1)}$ & 33.3 \\
\hline II & 0 & 0.0 \\
\hline IIIA & 0 & 0.0 \\
\hline IIIB & $1^{(2)}$ & 33.3 \\
\hline Closed & $1^{(3)}$ & 33.3 \\
\hline Total & 3 & 100.0 \\
\hline
\end{tabular}

Legend: $\mathrm{N}=$ Number of complications; \% = Percentage of complications; ${ }^{(1)}$ Pain, diminished range of motion (ROM) and, after removal of synthesis material, evolved with radial neuropraxia; (2) Infection; (3) Pain and diminished ROM.

Source: Present author.

\section{DISCUSSION}

It is now known from the literature that fixation of diaphyseal fractures of long bones should preferentially be done using the principle of relative stability, by means of minimally invasive techniques, thereby enabling formation of a bone callus.

The fixation technique using a bridge plate aims to achieve this objective. Without accessing the focus of the fracture, the fracture hematoma is maintained in its entirety, together with its periosteum, without aggression to the soft-tissue envelope, thus theoretically leading to greater speed in reaching consolidation ${ }^{(13)}$.
The present study demonstrated that, even in cases of fractures presenting a single line (which thus would traditionally be indicated for treatment aimed at absolute stability and compression between the fragments), use of the bridge plate technique was successful.

In the original technique described by Livani and Belangero $^{(13)}$, radioscopy was not used as an aid in reducing the fracture. It was reduced using the parameter of the intercondylar axis of the humerus, positioned perpendicularly to the axis of the biceps tendon, in order to correct any rotational displacement. The fixation was performed at $60^{\circ}$ of abduction so that varus would be avoided. In the present study, we observed that aligning the limb and obtaining bone contact (which are determining factors in fracture consolidation) were achieved more easily through using radioscopy.

In following up the patients, evolution of the bone callus was observed and it was found that in these fractures with a simple line, consolidation also occurred with formation of a bone callus, even though not as exuberantly as seen in long-bone fractures in the lower limbs. This perhaps occurs because of correlation with Wolf's law, which governs the use of forces and loads on the limb to stimulate the formation of bone callus, which does not occur profusely in the upper limbs.

By using long plates, as described in this study, stable synthesis is produced. The layout, number and location of the screws give rise to a wide working area, thus promoting relative stability.

Since this is a technique for relative stability, in which movement at the focus is necessary in order to stimulate bone callus formation, it could be seen that using two distal screws was sufficient for fixation, without the need for a third screw. There were only two situations in which it was decided to use three distal screws: in cases of fractures that went beyond the safety margin (i.e. $4.5 \mathrm{~cm}$ from the elbow joint along the greatest lever arm); and also in patients who presented poorer bone quality. In this manner, the minimally invasive technique was maintained. Kobayashi et $a l^{(15)}$ presented a contrary opinion, in stating that using three distal screws provided an early return to use of the limb. However, if using three screws was not possible, they recommended returning to the traditional fixation method, thereby abandoning the minimally invasive technique. Livani and Belangero $^{(13)}$ initially used three proximal and three distal 
screws in their work. In following up these patients, they noted that this method did not produce any profusion of callus, and they started to use two proximal and two distal screws.

The number of screws used in the present study was responsible for different speeds of consolidation. The patients in whom the technique used was similar to what was described by Livani and Belangero ${ }^{(13)}$ (with two proximal and two distal screws) achieve consolidation more rapidly. With increasing numbers of screws, the fracture consolidation rate gradually diminished.

The present study demonstrated that the greater the number of screws was, the longer the consolidation time was. This occurred particularly through diminished micromovement in the fracture and cyclicality of the synthesis material, caused by the greater stability that these screws provided. In the present study, there was a tendency towards faster consolidation in fractures treated with only four screws.

Positioning the plate on the anterior face of the humerus, without direct viewing of the radial nerve, as described by Belangero, enables a return to full range of motion of the shoulder and elbow. According to Livani and Belangero ${ }^{(13)}$, and Pospula and $\mathrm{Abu}$ Noor $^{(16)}$, in their respective series of patients treated using this method, shoulder range of motion was fully reestablished in all their patients.

However, all these studies showed that there could be limitations on elbow ROM in some cases. This was corroborated by the results from the present series, which showed a slight reduction in range of motion. Kobayashi et $a l^{(15)}$ explained that this limitation was due to positioning the plate more distally, i.e. very close to the elbow. They also suggested that injuries to the brachial muscle could be the genesis of the problem, although without well established results in the literature. Their results provides confirmation for what was found in the present study, since the technique described did not access the proximal or distal joints at any time in implementing it, thus respecting the limits of these joints and their capsules.

In the present study, we achieved a high consolidation rate, which occurred over a short time of postoperative evolution. The patients were able to attain a broad return of shoulder ROM and also an early return to their pre-trauma activities, with a high rate of patient satisfaction.

In the same way as described by Zafar and Porter ${ }^{(17)}$, the present study also showed that diaphyseal fractures of the humerus occurred in a variety of manners: transverse fractures, comminuted fractures and fractures through a mechanism of falling with the limb abducted, thereby leading routinely to fractures of spiral format.

As described earlier, this series demonstrated the same results as found by other authors, with regard to complications and associated lesions. Cases of high-energy trauma could be correlated with greater complication rates, as seen in the study by Livani and Belangero $^{(13)}$. Car accidents and firearm wounds were responsible for all such fractures presented in this study. This factor leads the present authors to think not only that the fracture type is responsible for whether the patient's evolution is favorable, but also that situations of severe compromising of the surrounding soft tissues, together with the altered clinical conditions inherent to the trauma mechanism, interfere with the consolidation process and increase the chances of complications.

In the present study, $50 \%$ of the patients presented associated lesions, thus demonstrating that the rate of severe fractures was high. This result was similar to that of the study by Livani and Belangero ${ }^{(13)}$, in which eight patients out of the total of fifteen presented associated lesions. The only case of infection occurred in multiple trauma victim, as described above.

It can be seen that although the complications made treatment more difficult, they made little difference to the final consolidation result. In the study by Livani and Belangero ${ }^{(13)}$, one patient presented loosening of the screws, yet the fracture consolidated.

All the cases in the present study presented improvements in their complications and evolved to consolidation. In the case in which infection occurred, it was important to discuss and delimit the causes that had led to the problem. This patient presented a floating elbow relating to high-energy trauma, with exposure of the fracture focus, and was classified as IIIB, according to the Gustilo and Anderson system ${ }^{(18)}$. For this reason, there was a need to use an external fixator in the emergency situation, with the aim of controlling the damage. The patient also presented associated infection at the fracture focus (a fracture in forearm bones), and he stated that he was a smoker.

Neuropraxia of the radial nerve is one of the most common complications of diaphyseal fractures of the humerus. In a study presented by Heim et $a l^{(19)}$, neuropraxia occurred frequently when the fixation method involving opening of the fracture focus was used, and it was also caused by the fracturing itself. From the results of this study, it can be suggested that 
improper and imprecise use of spacers may lead to injury of the radial nerve. This complication may be avoided through having a well-prepared team, with rigorous knowledge of the local anatomy and training in the surgical technique proposed. According to the technique of Livani and Belangero ${ }^{(13)}$, division of the brachial muscle is important in order to protect the radial nerve, thereby making the surgical technique possible without viewing and dissecting this nerve. It should also be emphasized that this muscle has double innervation, such that the medial belly is innervated by the musculocutaneous nerve and the lateral belly by the radial nerve. Thus, the brachial muscle can be divided in the middle, along its entire length, without the posterior portion losing its function.

Another cause that is unavoidable is neuropraxia relating to the fracturing or the injury mechanism. In the present study, this was confirmed through the presence of three cases with neuropraxia due to firearm wounds.

It might be imagined that this technique is still not accepted by the majority of surgeons because it is new and its preliminary results have not yet become widely known, or perhaps through fear. Nonetheless, it was found in this study that the minimally invasive bridge plate technique could be performed rapidly and presented an esthetic result that was better than that of the open fixation technique, with better acceptance by the patient.

Like in most bridge plate techniques, the difficulty in it is that the procedure for removing the synthesis

\section{REFERENCES}

1. Bhandari M, Devereaux PJ, McKee MD, Schemitsch EH. Compression plating versus intramedullary nailing of humeral shaft fractures - a meta-analysis. Acta Orthopaedica. 2006; 77(2): 279-284.

2. Changulani M. Comparison of the use of the humerus intramedullary nail and dynamic compression plate for the management of diaphyseal fractures of the humerus. A randomised controlled study. International orthopaedics (SICOT). 2007; 31: 391-395.

3. Cheng HR, Lin J. Prospective Randomized Comparative Study of Antegrade and retrograde Locked Nailing for Middle Humeral Shaft Fracture. The Journal of TRAUMA Injury, infection, and Critical Care. 2008; 65: 94-102.

4. Rutgers $M$, Ring $D$. Treatment of diaphyseal fractures of the humerus using a functional brace. J Orthop Trauma. 2006;20(9):597-601.

5. Ekholm R, Tidermark J, Törnkvist H, Adami J, Ponzer S. Outcome after closed functional treatment of humeral shaft fractures. J Orthop Trauma. 2006;20(9):591-6.

6. Chapman JR, Bradford HB, Agel J, Benca PJ. Randomized Prospective Study of Humeral Shaft Fracture Fixation: Intramedullary Nails Versus Plates. Journal of Orthopaedic Trauma. 2000;14(3): 162-166.

7. McKee MD. Fracture of the shaft of the humerus. In: Bucholz RW, Heckman JD, Court-Brouwn CM, eds. Rockwood and Green's Fractures in Adults. Philadelphia, PA: Lippincott Wiliams \& Wilkins; 2006. p. 1117-1159

8. Chen AL, Thomas MS, Joseph N, Wolinsky PR, Tejwani NC, Kummer FJ et. al. Fixation Stability of Cominuted Humeral Shaft Fractures: Locked Intramedullary Nailing versus Plate Fixation. J Trauma. 2002; 53: 733-737.

9. Lin, J. Treatment Of Humeral Shaft Fractures with Humeral Locked Nail and Comparison with Plate Fixation. The Journal of TRAUMA Injury, infection, and Critical Care. 1998; 44(5): 859-864

10. McCormack RG, Brien D, Buckley RE, McKee MD, Powell J, Schemitsch EH. Fixation material becomes more complicated. The risk of nerve injury may be higher and, in some cases, wider access may be needed.

The factors causing bias in the present study that can be highlighted include the non-homogeneity of the sample and the fact that only two surgeons with training in the bridge plate technique were used for the surgical procedures. Further studies will be necessary, in order to evaluate patients in different age groups. Elderly patients may present poor bone quality, which is an unfavorable biological factor. In our view, this disadvantage becomes one of the main factors in the worse evolution of these patients.

The results presented have allowed bridge plates to come into routine use in our service. Thus, a protocol has been drawn up in which patients with fractures of the humerus presenting a surgical indication will, regardless of the characteristics of the fracture line, be treated in a minimally invasive manner unless they present the exclusion criteria set out earlier.

\section{CONCLUSION}

The authors believe that managing diaphyseal fractures of the humerus using the principles of biological fixation by means of a bridge plate, with an anterior approach, constitutes a useful tool for orthopedists' day-to-day practice. This technique presents low rates of complications and morbidity, good initial results, full rehabilitation and good patient satisfaction, although the present series was limited by the small sample size.

of fractures of the shaft of the humerus by dynamic compression plate or intramedullary nail - A prospective randomised trial. J Bone Joint Surg [Br] 2000; 82(B): 336-9.

11. Virkus WV, Goldberg SH, Lorenz EP. A comparison of Compressive Force Generation by Plating and Intramedullary Nailing Techniques in a Tranverse Diaphyseal Humerus Fracture Model. The Journal of TRAUMA Injury, infection, and Critical Care. 2008; 65: 103-108.

12. Ziran BH, Belangero WD, Livani B, Pesantez R. Percutaneous Plating of the humerus with locked Plating: Technique and Case Report. J Trauma, 2007; 63: 205-210.

13. Livani B, Belangero WD. Bridging plate osteosynthesis of humeral shaft fractures. Injury, Int. J. Care Injured. 2004; 35: 587-595.

14. Zhiquan A, Bingfang Z, Yeming W, Chi Z, Peiyan H, MD. Minimally Invasive Plating Osteosynthesis (MIPO) of Middle and Distal Third Humeral Shaft Fractures. J Orthop Trauma. 2007; 21: 628-633.

15. Kobayashi M, Watanabe $Y$, Matsushita T. Early full range of shoulder and elbow motion is possible after minimally invasive plate osteosynthesis for humeral shaft fractures. J Orthop Trauma. 2010; 24(4): 212-6.

16. Pospula W, Abu Noor T. Percutaneous fixation of comminuted fractures of the humerus: initial experience at Al Razi hospital, Kuwait. Med Princ Pract. 2006; 15(6): 423-6

17. Zafar MS, Porter K. Humeral shaft fractures: a review of literature. Trauma. 2007; 9: 273-282.

18. Gustilo RB, Anderson JT. Prevention of Infection in the treatment of one thousand and twenty-five open fractures of long bones: retrospective and prospective analyses. J. Bone Joint Surg AM. 1976; 58: 453-458.

19. Heim D, Herkert F, Hess $P$, Regazzoni P. Surgical treatment of humeral shaft fractures - the Basel experience. J Trauma. 1993; 35(2): 226-32. 